\title{
Role of Alpha Adrenoceptors in Opossum Internal Anal Sphincter
}

Shigeru Yamato and Satish Rattan

Divisions of Gastroenterology and Hepatology, Beth Israel Hospital, Harvard Medical School, Boston, Massachusetts 02215; Jefferson Medical College, Philadelphia, Pennsylvania 19107

\begin{abstract}
The purpose of the present investigation was to examine the role of alpha adrenoceptors in the internal anal sphincter (IAS). Studies were performed on alpha-chloralose anesthetized opossums. Resting pressure in the IAS (IASP) was recorded using low compliant continuously perfused catheters. The effects of the alpha-1 adrenoceptor agonist phenylephrine and alpha-2 adrenoceptor agonist clonidine and their corresponding selective antagonists, prazosin and yohimbine, respectively, were examined on the resting IASP, and on rectal balloon distension (RBD)-mediated IAS relaxation.

Phenylephrine caused a rise in the IASP that was blocked by prazosin and not by yohimbine. Phenylephrine had no effect on IAS relaxation caused by RBD. Clonidine on the other hand caused significant suppression of IAS relaxation in response to RBD, but caused minimal changes in the resting IASP. The suppression of IAS relaxation by clonidine was selectively antagonized by yohimbine but not by prazosin. From these studies we conclude that alpha-2 adrenoceptors exert important neuromodulatory influences on rectoanal inhibitory reflex, while alpha-1 adrenoceptors may exert modulatory effects on the resting IAS tone. (J. Clin. Invest. 1990. 86:424-429.) Key words: internal anal sphincter • alpha adrenoceptors $\bullet$ rectoanal inhibitory reflex $\bullet$ anal canal pressures
\end{abstract}

\section{Introduction}

The internal anal sphincter (IAS) ${ }^{1}$ plays an important role in recto-anal continence and in the pathophysiology of diarrhea and constipation (1). In vitro studies from different laboratories in different species (2-4) have suggested that resting tone in the IAS is primarily due to the myogenic properties of the IAS smooth muscle. Relaxation of IAS on the other hand is neural and involves the release of noncholinergic, nonadrenergic inhibitory neurotransmitter $(2,5)$ from the myenteric inhibitory neurons.

Sympathetic nerve stimulation in vivo studies is known to cause a rise in the resting IAS pressure (IASP) and suppression

Address reprint requests to Dr. Satish Rattan, Department of Medicine, Division of Gastroenterology and Hepatology, Jefferson Medical College, 901 College, 1025 Walnut Street, Philadelphia, PA 19107.

Received for publication 8 August 1989 and in revised form 30 March 1990.

1. Abbreviations used in this paper: EAS, external anal sphincter; IAS, internal anal sphincter; IASP, IAS pressure; MAP, mean arterial pressure; RBD, rectal balloon distension; TTX, tetrodotoxin.

J. Clin. Invest.

(c) The American Society for Clinical Investigation, Inc. $0021-9738 / 90 / 08 / 0424 / 06 \$ 2.00$

Volume 86, August 1990, 424-429 of rectal balloon distension (RBD)-mediated IAS relaxation. Sympathetic fibers to the IAS that terminate in the area of the myenteric neurons or directly at the smooth muscle (6) may exert their effects on the IAS via alpha or beta adrenoceptors $(7,8)$. Beta adrenoceptors are primarily inhibitory and produce relaxation of the IAS by their action directly at the smooth muscle $(7,8)$. Alpha adrenoceptors may further be subclassified into alpha-1 and alpha-2.

The location and the role of alpha- 1 and alpha- 2 adrenoceptors in a number of systems has been examined before (9-11). However, studies examining the influence of alpha-1 and alpha-2 agonists in order to investigate the role of alpha adrenoceptors in IAS function have not been performed before.

The purpose of this investigation therefore was to investigate the role of alpha adrenoceptors in the regulation of the IAS.

\section{Methods}

Animal preparation. Studies were performed on 42 adult opossums anesthetized with alpha-chloralose. The animals were strapped supine on an animal board and kept warm $\left(36^{\circ} \mathrm{C}\right)$ with a circulating water heating pad. The femoral vein was cannulated for intravenous administration and the femoral artery was cannulated (intraarterially) to position the tip of the cannula at the level of bifurcation of the common iliac arteries. The intraarterial cannula was used for the injection of alpha adrenergic agonists and antagonists, and for the continuous monitoring of arterial blood pressure. The position of the intraarterial cannula was confirmed at the conclusion of the experiment. The animals were supported by an artificial ventilator (model 661; Harvard Apparatus Co. Inc., Millis, MA) via an endotracheal tube.

Intraluminal pressure measurements. Anal canal pressures reflect total activity of the IAS smooth muscle and external anal sphincter (EAS) and other adjoining skeletal muscles. In order to record pressures contributed by the IAS, the electromyographic activity of the EAS was obliterated by the use of pancuronium bromide $(1 \mathrm{mg} / \mathrm{kg}$ i.v.). The use of pancuronium selectively obliterated the electromyographic activity of the EAS without any effect on the resting IASP and its response to rectoanal reflex (12). A modified version of the specially designed seven channel manometry catheter assembly with side holes 5-mm apart was used to record IASP. All the catheters of the assembly were continuously perfused with bubble-free water via a low compliance, pneumo-hydraulic valve system. The catheter assembly was initially introduced into the rectum and with a slow pull through it was positioned in the anal canal so that pressures from the entire length of the anal canal could be recorded simultaneously. High pressures in the internal anal sphincter consisted of rhythmic fluctuations (phasic) superimposed on the tonic pressures. Tonic pressures were defined as the elevated pressures and denoted by the line joining the valleys of rhythmic fluctuations. Scanning the entire anal canal, spontaneous highest phasic pressures with superimposed tonic pressures that responded to RBD were regarded as the resting IASP. IASPs were recorded on a dynograph recorder (model R711; Beckman Instruments, Inc., Schiller Park, IL). All the pressures were in relation to the atmosphere and were recorded using Statham transducers. The details of construction of the recording catheter assembly, pressure dynamic of the as- 
sembly, and other details of the pressure recording system have also been described previously (12)

Drug responses. The IAS response to intraarterial phenylephrine and clonidine administered in single boluses in different randomized doses (ranging from $1 \times 10^{-8}$ to $1 \times 10^{-5} \mathrm{~mol} / \mathrm{kg}$ ) were examined. The corresponding antagonists of alpha-1 and alpha-2 adrenoceptors prazosin and yohimbine were also given via the same route in different doses so as to investigate their effectiveness in blocking the effects of their respective agonists. Details of quantification of recording and representation of changes in baseline IASP after administration of an agent has been described previously (12). Alpha-1 adrenoceptor agonist was delivered at a minimum of 20 -min intervals or at least $10 \mathrm{~min}$ following the disappearance of the effect of the previously administered dose, since rise in the resting IASP caused by phenylephrine was short lived and reversible. An interval of $10 \mathrm{~min}$ was allowed between administration of the antagonist and alpha- 1 agonist. In the case of the experiments for clonidine's effect on the IAS relaxation, the interval between different doses of clonidine was fixed at $30 \mathrm{~min}$. Considering the long-lasting actions of clonidine, the possibility that the quantitative values of IAS relaxation with RBD in the presence of different doses of clonidine are the result of partial accumulation may not be ruled out. For studies dealing with alpha adrenoceptors antagonists, clonidine $\left(6.4 \times 10^{-7} \mathrm{~mol} / \mathrm{kg}\right)$ was present throughout the experiment and the influence of different doses of antagonists on the suppressant effect of clonidine on RBD responses was investigated.

Tetrodotoxin (TTX) $(5 \mu \mathrm{g} / \mathrm{kg}$, i.a.) was given in single doses at 30-min intervals until the IAS relaxation responses to RBD were completely obliterated. The effect of phenylephrine on the IAS in the presence of TTX was examined when IAS responses to RBD were completely obliterated.

The following agents were used: clonidine hydrochloride (Catapres; mol wt 230.10; Boehringer Ingelheim Ltd., Elmsford, NY); alpha chloralose (mol wt 309.5); naphazoline hydrochloride (mol wt 246.7); phenylephrine hydrochloride (mol wt 203.77); prazosin hydrochloride (alpha-1 adrenoceptor antagonist [13]; mol wt 419.9); yohimbine hydrochloride (alpha-2 adrenoceptor antagonist [14]; mol wt 390.9; Sigma Chemical Co., St. Louis, MO); pancuronium bromide (Organon Diagnostics, West Orange, NJ); and TTX (mol wt 319.28; Calbiochem-Behring Corp., San Diego, CA).

All agents except prazosin and yohimbine were dissolved or diluted in $0.9 \% \mathrm{NaCl}$. Prazosin and yohimbine were dissolved in distilled water and then diluted with $0.9 \% \mathrm{NaCl}$. The administration of the solvent in all cases was tested in control experiments and used in the volumes employed for the actual agents that were found to exert no significant effect on the internal anal sphincter. The doses of all agents were expressed on the basis of their salts.

Hypogastric nerve stimulation. Laparotomy was performed and the point of bifurcation of the common iliac arteries was identified to locate the hypogastric plexus. One of the nerves emerging from the plexus was used and upon electrical stimulation elicited maximum rise in IASP. Bipolar silver-silver chloride hook stimulating electrodes were placed around the nerves for electrical stimulation of the sympathetic nerves. The parameters of electrical stimulation were $5 \mathrm{~mA}, 0.5 \mathrm{~ms}$ pulse duration, $60 \mathrm{~s}$ train at frequencies varying from 1 to $20 \mathrm{~Hz}$

Recto-anal reflex. To mimic the rectoanal reflex, RBD was provided by $8 \mathrm{~s}$ inflations of the rectal balloon. The volume of distension was varied from 1 to $10 \mathrm{ml}$ of air. In order to quantify the influence of alpha adrenoceptor agonists on IAS relaxation, the volume of RBD was such that it produced maximal relaxation of IAS. This was determined in each animal beforehand. Details of the construction of the rectal balloon (as part of the pressure recording assembly) and its use have been described before (12).

Sacral nerve stimulation and local intramural stimulation. The sacral nerve which produced maximal IAS relaxation on electrical stimulation was used. Two sacral nerves were found in these animals as compared to five in our previous studies (15). The exact reason for the difference is not known. For certain experimental protocols, electrodes were implanted in the region of the IAS for local intramural stimulation as previously described (5).

Data analysis. The response of resting IASP to different drugs was measured as the maximal change in peak phasic pressure following administration of the agents and different neural stimuli. In order to account for possible variations in resting peak pressures, the changes in IASP were expressed both on the basis of percent as well as absolute changes. Furthermore, each animal served its own control for data regarding responses to different agents, hypogastric nerve stimulation, $\mathrm{RBD}$, sacral nerve stimulation, and local intramural stimulation. In case more than one observation was made in response to a specific dose or stimulus parameter in a given experimental protocol, the average of the responses was treated as $n=1$. Data are expressed as mean $\pm \mathrm{SE}$ of four to six values obtained in different animals. Statistical analysis was performed using paired or unpaired $t$ test where applicable (16).

\section{Results}

Effect of alpha-1 adrenoceptor agonist phenylephrine on the resting IASP and on IAS relaxation by $R B D$. Phenylephrine caused dose-dependent rises in the resting IASP. Rises in both phasic as well as tonic pressures were observed. Fig. 1 provides the detailed changes in IASP with phenylephrine on an absolute and percentile basis. The rise in IASP with $1.6 \times 10^{-7}$ $\mathrm{mol} / \mathrm{kg}$ was $52.5 \pm 9.0 \mathrm{mmHg}$ and $88.8 \pm 11.1 \%$ (the resting IASP was $60.0 \pm 7.8 \mathrm{mmHg}$ ). The changes in maximal tonic pressure with different doses of phenylephrine paralleled with those of maximal phasic pressure (IASP). The absolute rise in tonic pressures with $1.6 \times 10^{-7}$ and $6.4 \times 10^{-7} \mathrm{~mol} / \mathrm{kg}$ were $45.0 \pm 6.1$ and $48.3 \pm 1.7 \mathrm{mmHg}$, respectively (the resting tonic pressures in the IAS in these experiments were 24.0 0.4 and 23.3 $\pm 4.4 \mathrm{mmHg}$, respectively).

Interestingly, when the pressures in each level of the anal canal were analyzed, the rise in pressures with phenylephrine were dependent on the region of the anal canal. Tested against $1.6 \times 10^{-7} \mathrm{~mol} / \mathrm{kg}$ phenylephrine, the proximal part of the anal canal ( 2.5 and $3 \mathrm{~cm}$ above the anal verge) produced a significantly higher response than the distal part (1 and $1.5 \mathrm{~cm}$ above anal verge). The absolute values of rise in phasic pres-

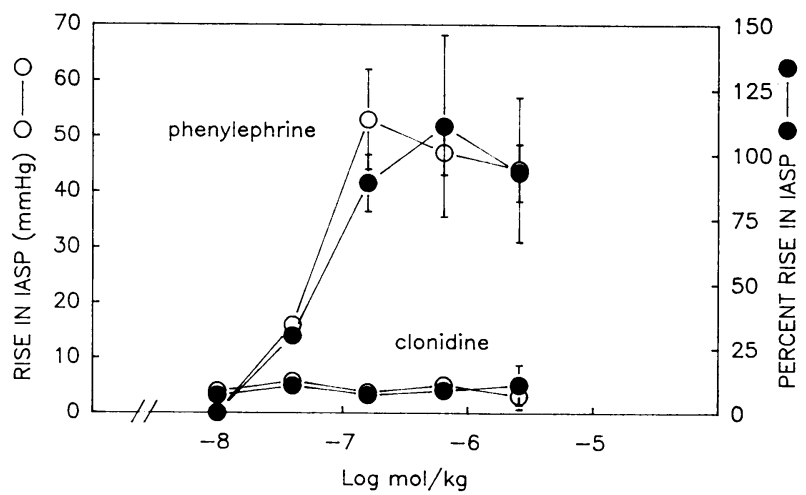

Figure 1. Effects of phenylephrine and clonidine on maximal peak phasic IASP. Phenylephrine caused a dose-dependent rise in IASP. The rise in IASP with phenylephrine is shown on both the absolute and percent bases. The dose of $1.6 \times 10^{-7} \mathrm{~mol} / \mathrm{kg}$ is maximally effective in causing a rise in IASP with phenylephrine. Clonidine, on the other hand, caused no significant change in IASP. This and the subsequent figures were plotted using sigma plot. The values represent mean $\pm \mathrm{SE}$, in some cases the $\mathrm{SE}$ were small and the absence of the SE bars is due to their loss in the symbols. 
sure at 1,2 , and $3 \mathrm{~cm}$ above the anal verge were $9.0 \pm 2.8$, $27.0 \pm 7.1$, and $75.5 \pm 13.3 \mathrm{mmHg}$, respectively.

The neurotoxin tetrodotoxin in the present studies like the previous studies failed to modify the rise in IASP caused by phenylephrine (12).

The alpha- 1 agonist phenylephrine examined over a wide range of doses produced no significant effect on the fall in IASP caused by RBD (Fig. 2).

Influence of alpha-1 adrenoceptor antagonist prazosin on rise in IASP with phenylephrine and by hypogastric nerve stimulation. Prazosin antagonized rises in both resting IASP and mean arterial pressure (MAP) in response to phenylephrine. In order to arrive at an appropriate dose of prazosin, we examined the influence of different doses of prazosin against 6.4 $\times 10^{-7} \mathrm{~mol} / \mathrm{kg}$ phenylephrine which was maximally effective in causing a rise in MAP and $1.6 \times 10^{-7} \mathrm{~mol} / \mathrm{kg}$ which was most effective in causing a rise in IASP. $6.4 \times 10^{-7} \mathrm{~mol} / \mathrm{kg}$ phenylephrine caused a rise in MAP of $25.4 \pm 3.8 \mathrm{mmHg}$. Prazosin caused a dose-dependent antagonism of this rise. The rise in MAP with phenylephrine in the presence of prazosine 10,25 , and $50 \mu \mathrm{g} / \mathrm{kg}$ was $14.0 \pm 2.3,11.3 \pm 2.9$, and $3.5 \pm 1.9$ $\mathrm{mmHg}$, respectively. Likewise the rise in IASP with $1.6 \times 10^{-7}$ $\mathrm{mol} / \mathrm{kg}$ phenylephrine was also maximally antagonized from $52.5 \pm 9.0$ to $3.5 \pm 1.9 \mathrm{mmHg}$ in the presence of prazosin $(50$ $\mu \mathrm{g} / \mathrm{kg}$ ). The resting IASP before and after prazosin were $60.0 \pm 7.8$ and $50.0 \pm 9.6 \mathrm{mmHg}$, respectively.

Electrical stimulation of hypogastric nerves caused a frequency-dependent rise in IASP (Fig. 3) and MAP. The rise in IASP with a $10-\mathrm{Hz}(5 \mathrm{~mA}, 0.5 \mathrm{~ms}, 60 \mathrm{~s}$ train) stimulation of the hypogastric nerve was $39.2 \pm 5.5 \mathrm{mmHg}$. Prazosin $(50 \mu \mathrm{g} / \mathrm{kg}$ ) caused a significant decrease in the rise in IASP caused by hypogastric nerve stimulation to $17.9 \pm 3.3 \mathrm{mmHg}(P<0.05)$.

In addition to causing a rise in IASP, sympathetic nerve stimulation also causes inhibition of fall in IASP in response to RBD (17).

Influence of alpha-1 adrenoceptor antagonist prazosin on the resting IASP. The fall in the resting IASP with the dose of prazosin $(50 \mu \mathrm{g} / \mathrm{kg})$ that was optimal in causing the antagonism of rise in IASP in response to phenylephrine and hypogastric nerve stimulation was not significant. The resting values of IASP before and after prazosin $(50 \mu \mathrm{g} / \mathrm{kg})$ were 74.3 \pm 6.6 and $60.7 \pm 9.4 \mathrm{mmHg}(P>0.05 ; n=16)$. However,

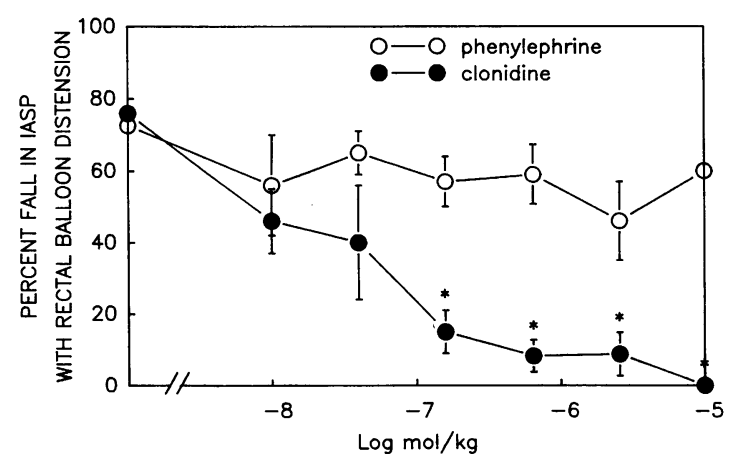

Figure 2. Effects of phenylephrine and clonidine on RBD-induced IAS relaxation. Clonidine caused dose-dependent and significant suppression of IAS relaxation caused by $\operatorname{RBD}(P<0.05)$. Certain doses of clonidine caused complete obliteration of IAS relaxation in response to RBD. Phenylephrine on the other hand caused no significant modification in the fall of IASP by RBD.

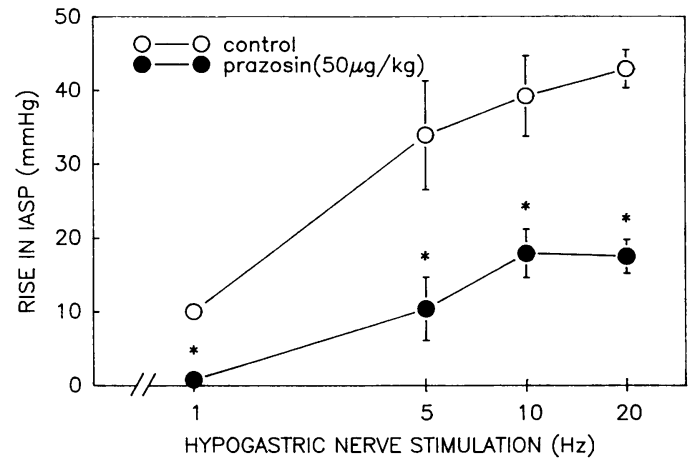

Figure 3. Effect of prazosin on the rise in IASP caused by hypogastric nerve stimulation. $50 \mu \mathrm{g} / \mathrm{kg}$ of prazosin caused significant antagonism of hypogastric nerve stimulation-induced rise in IASP.

the higher doses of prazosin produced significant fall in IASP (Fig. 4).

Like phenylephrine, prazosine $(50 \mu \mathrm{g} / \mathrm{kg})$ affected the pressure depending upon the level of the anal canal. In the distal part of the anal canal, prazosin had no significant effects, while proximally ( 2 and $2.5 \mathrm{~cm}$ above anal verge), it caused a significant fall. The exact significance of these observations at the present time is not clear.

Effects of alpha-2 adrenoceptor agonist clonidine on the resting $I A S P$ and on $I A S$ relaxation by $R B D$. As compared to the effects of phenylephrine, clonidine had minimal effects on the resting IASP (Fig. 1).

The alpha-2 adrenoceptor agonist clonidine (in contrast to alpha-1 agonist) caused significant suppression of fall in IASP by $\operatorname{RBD}(P<0.05)$. At a dose of $6.4 \times 10^{-7} \mathrm{~mol} / \mathrm{kg}$ clonidine, an almost complete obliteration in the IAS relaxation in response to RBD was observed (Fig. 2). This effect of clonidine was maintained for at least $2 \mathrm{~h}$. The entire protocol dealing with the effect of clonidine and antagonists was completed within that time. In these experiments, the resting IASP before and after clonidine $\left(6.4 \times 10^{-7} \mathrm{~mol} / \mathrm{kg}\right)$ were $68.5 \pm 4.6$ and $73.4 \pm 4.2 \mathrm{mmHg}$, respectively $(P>0.05)$.

Influence of alpha-2 adrenoceptor antagonist yohimbine on the effect of clonidine. In doses of $250 \mu \mathrm{g} / \mathrm{kg}$ and higher, yohimbine produced dose-dependent antagonism of clonidine $\left(6.4 \times 10^{-7} \mathrm{~mol} / \mathrm{kg}\right)$ in causing inhibition of RBD-induced IAS relaxation (Fig. $5 \mathrm{~A})$. Yohimbine $(625 \mu \mathrm{g} / \mathrm{kg})$ caused complete

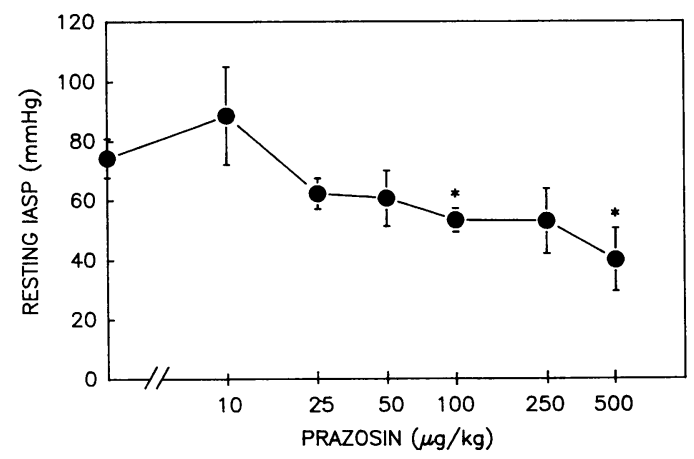

Figure 4. Effect of prazosin on resting IASP recorded in 16 animals. Note that $50 \mu \mathrm{g} / \mathrm{kg}$ of prazosin did not significantly modify the resting IASP $(P>0.05)$. The higher dose of prazosin did however cause a significant fall in IASP $(P<0.05)$. 
reversal of the clonidine-induced suppression of IAS relaxation without significant change in the resting IASP. Prazosin $(50 \mu \mathrm{g} / \mathrm{kg})$, which almost abolished the response of phenylephrine, had no significant effect on the response of clonidine in causing suppression of IAS relaxation (Fig. $5 B$ ).

Influence of clonidine on fall in IASP caused by sacral nerve and local intramural stimulation. Electrical stimulation of sacral nerve and local intramural stimulation caused IAS relaxation. The fall in IASP produced by the stimulation of the sacral nerve was not modified by the alpha- 2 agonist clonidine $\left(6.4 \times 10^{-7} \mathrm{~mol} / \mathrm{kg}\right)$ (Fig. 6). Even the higher dose of clonidine $\left(1.0 \times 10^{-5} \mathrm{~mol} / \mathrm{kg}\right)$ failed to cause significant modification of IAS relaxation caused by sacral nerve stimulation. At 2 and 5 $\mathrm{Hz}$, the fall in IASP before and after clonidine $\left(1 \times 10^{-5} \mathrm{~mol} /\right.$ $\mathrm{kg}$ ) was $73.0 \pm 1.0$ and $79.0 \pm 1.0$, and $77.0 \pm 1.5$ and $81.0 \pm 0.8 \%$, respectively $(P>0.05)$. The resting IASP during the control experiments at the time of 2 and $5 \mathrm{~Hz}$ of sacral nerve stimulation were $38.3 \pm 1.7$ and $38.1 \pm 1.2 \mathrm{mmHg}$, respectively.

Clonidine, in the dose $\left(6.4 \times 10^{-7} \mathrm{~mol} / \mathrm{kg}\right)$ that caused almost complete obliteration of IAS relaxation response to RBD failed to modify IAS relaxation elicited with local intramural stimulation. The fall in IASP with local stimulation before and after clonidine was $78.5 \pm 3.1$ and $80.2 \pm 2.9 \%(P$
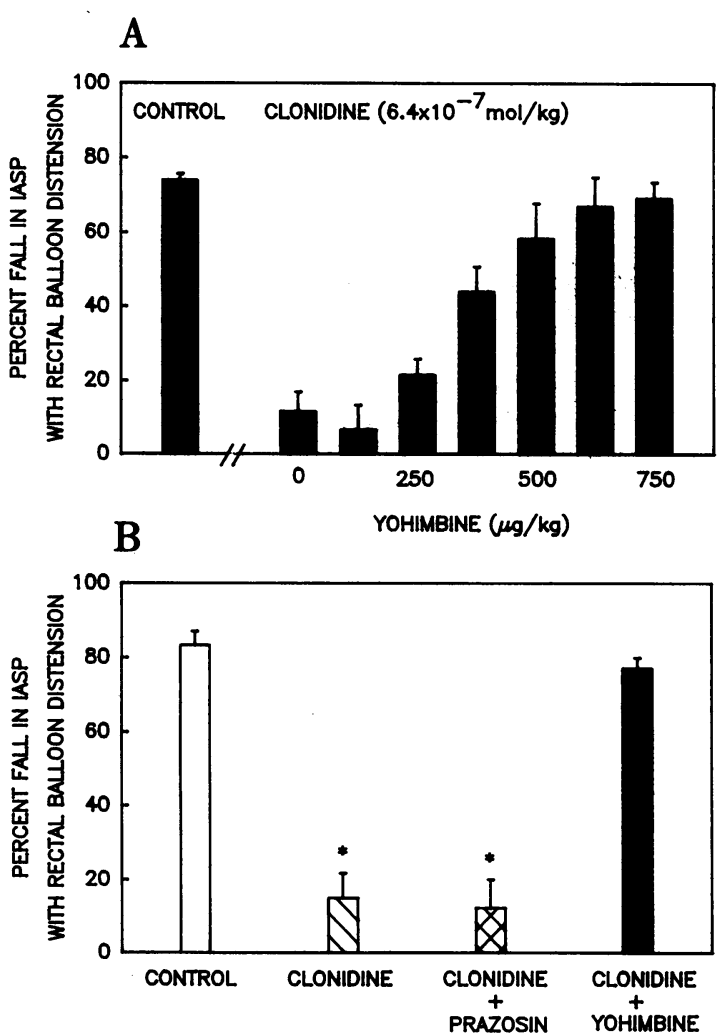

Figure 5. (A) Effect of yohimbine on clonidine-induced inhibition of IAS relaxation caused by RBD. Note that yohimbine caused a dosedependent reversal of the IAS relaxation. It was complete with the $625 \mu \mathrm{g} / \mathrm{kg}$ and higher doses. Note that for clarity, 250, 500, and 750 $\mu \mathrm{g} / \mathrm{kg}$ doses of yohimbine were only labeled on the graph and the doses of 125,375 , and $625 \mu \mathrm{g} / \mathrm{kg}$ were not labeled. $(B)$ Effect of prazosin and yohimbine on RBD-induced IAS relaxation. Clonidine caused significant suppression of IAS relaxation by RBD, which was reversed by yohimbine. The suppression of RBD-induced IAS relaxation with clonidine was not affected by prazosin.
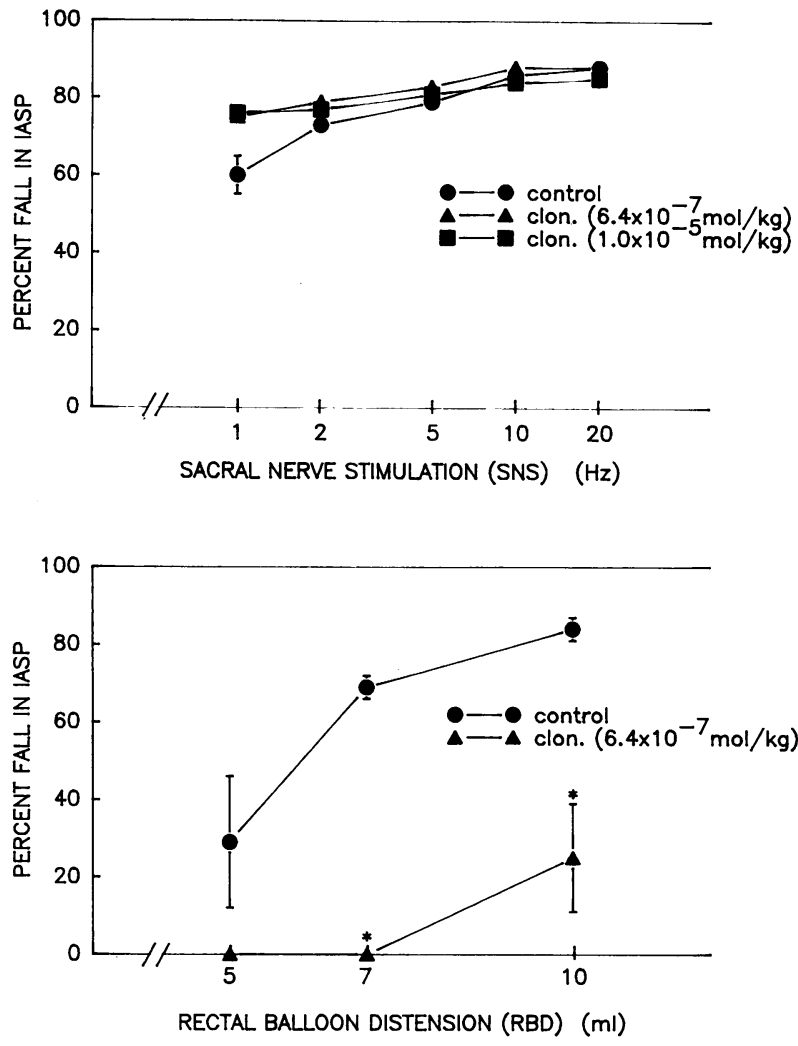

Figure 6. Effect of clonidine on sacral nerve stimulation and RBDinduced fall in IASP. Note that in this series of experiments, the fall in IASP in response to RBD was almost abolished (lower panel) while the response to sacral nerve stimulation in causing IAS relaxation was still preserved (upper panel).

$>0.05)$. The fall in IASP with RBD $(7 \mathrm{ml})$ in this set of experiments, before and after clonidine, was $85.4 \pm 4.3$ and $4.0 \pm 0 \%$, respectively $(P<0.05)$

Effect of naphazoline on the internal anal sphincter. Naphazoline $\left(6.4 \times 10^{-7} \mathrm{~mol} / \mathrm{kg}\right)$ caused two types of responses on IAS, a rise in IASP and suppression of fall in IASP produced by RBD. The fall in IASP with RBD $(7 \mathrm{ml})$ before and after naphazoline was $66.7 \pm 4.7$ and $8.6 \pm 3.8 \%$, respectively $(P$ $<0.05$ )

\section{Discussion}

The results of the present investigation suggest that alpha adrenoceptors exert significant effects on the internal anal sphincter. Alpha-2 adrenoceptors exert neuromodulatory effects on IAS relaxation primarily in response to RBD. The observations in support of this are that the alpha-2 adrenoceptor agonist clonidine caused almost complete obliteration of IAS relaxation elicited by RBD. A number of previously published studies in different systems have suggested the presynaptic location of alpha-2 adrenoceptors and the site of action of clonidine $(9-11,18,19)$. The action of alpha-2 adrenoceptor agonist clonidine and its site of action on the IAS however, have not been examined before.

The neural pathway responsible for IAS relaxation in response to RBD has not been fully characterized. A number of studies have suggested that the pathway is intramural (20-22). 
On the other hand, involvement of the spinal cord (presumably via sacral nerves) may not be completely ruled out (23). This study showed that clonidine caused obliteration of IAS relaxation in response to $R B D$ without modifying the responses to sacral nerve stimulation and local intramural stimulation. These findings suggest that the inhibitory effect of clonidine at the IAS smooth muscle and neuromuscular level is less likely, since the fall in IASP in response to the released inhibitory neurotransmitter substance (in response to sacral nerve stimulation and local intramural stimulation), which in turn acts on the IAS smooth muscle (17), remained unmodified by clonidine. Thus the site of action of clonidine is suggested to be above the neuromuscular level and possibly at the intramural inhibitory pathway. The central site of action of clonidine in other regions of the gastrointestinal tract has been suggested before (24-27). The central site for the suppressant effect of clonidine on the recto-anal inhibitory reflex is less likely since RBD-induced IAS relaxation may be due primarily to activation of the intramural inhibitory pathway. Furthermore, naphazoline, a putative alpha-2 adrenoceptor agonist that crosses the blood brain barrier poorly (24), also blocks RBD-induced IAS relaxation.

In contrast to the alpha- 2 adrenoceptors, alpha-1 adrenoceptors reside in the smooth muscle cells $(10,11)$. The present studies on IAS support that concept since the alpha-1 adrenoceptor agonist phenylephrine-induced rise in IASP was not modified by neurotoxin TTX, and it did not exert significant neuromodulatory effects on the IAS (evident by the lack of inhibitory effect on the IAS relaxation). Furthermore, prazosin, which works by the antagonism of alpha-1 adrenoceptors at the smooth muscle level (13), caused selective antagonism of the action of phenylephrine without modifying the effect of clonidine, an alpha- 2 adrenoceptor agonist.

In this study we examined the effects of different doses of a more selective alpha-1 adrenoceptor antagonist, prazosin, and examined the influence of the antagonist along the entire length of the anal canal. The data suggest that the effect of alpha- 1 activation and antagonism show local variation within the anal canal. Alpha-1 adrenoceptor agonist and antagonist had more pronounced effects on the proximal part of the anal canal, suggesting that the pressures in this part of the anal canal may be partially under excitatory modulation by sympathetic nerve via the alpha-1 adrenoceptors. The resting pressures in the distal part of the anal canal, however, were not significantly modified. The exact significance of differential responses of different regions of the anal canal to the alpha-1 adrenoceptor agonists and antagonists is not clear at the present time. Differential sensitivities to a given neurohumoral substance in different regions of the large intestine are just beginning to be recognized (28). Interestingly, when studies were performed focussing on the maximal peak phasic pressures of the whole anal canal (IASP), minimal effects with the optimal dose of prazosin were observed. The higher doses of prazosin however did cause a significant fall in the resting IASP. The exact reason for the fall in IASP with higher doses of prazosin other than the possible nonselectivity of its action is not known. The lack of exact scrutiny of IASP along the entire length of the anal canal, different doses of selective antagonist of alpha-1 adrenoceptors, the use of a large manometry device, and the species differences may have contributed to the differences in results with alpha- 1 adrenoceptors' antagonists on the resting IASP (29). Future studies examining the participation of longitudinal versus circular smooth muscle fibers of IAS may improve our understanding of different neurohumoral factors influencing the resting IASP.

From these studies we conclude: $(a)$ the activation of alpha-2 adrenoceptors exerts major inhibitory modulatory actions on the recto-anal inhibitory reflex causing suppression of reflex-mediated IAS relaxation. The exact site of alpha-2 adrenoceptor-mediated suppression of IAS relaxation remains to be further investigated; $(b)$ alpha-1 adrenoreceptors exert primarily excitatory effects on the IAS smooth muscle.

\section{Acknowledgments}

The authors thank Dr. Donald O. Castell and Dr. Willis C. Maddrey for the institutional and departmental support from Jefferson Medical College of Thomas Jefferson University. We thank Drs. A. Sengupta, S. Nurko, and S. Chakder for their helpful criticism, B. Ransil for the use of computer resources for statistical analysis, and Wendy-Sue Porter for technical assistance.

This work was supported by grant DK-35385 from the National Institutes of Health. Dr. Yamato is recipient of a fellowship from the National Medical Center of Japan.

\section{References}

1. Schiller, L. R. 1989. Fecal incontinence. In Gastrointestinal Disease: Pathophysiology, Diagnosis, Management. M. H. Sleisenger and J. S. Fordtran, editors. 4th ed. W. B. Saunders Co., Philadelphia. 317-331.

2. Biancani, P., J. Walsh, and J. Behar. 1985. Vasoactive intestinal peptide: a neurotransmitter for relaxation of the rabbit internal anal sphincter. Gastroenterology. 89:867-874.

3. Lim, S. P., and T. C. Muir. 1985. Mechanisms underlying the electrical and mechanical responses of the guinea pig internal anal sphincter to field stimulation and to drugs. Br. J. Pharmacol. 86:427437.

4. Nissan, S., Y. Vinograd, A. Hadari, P. Merguerian, A. Zamir, O. Lernau, and M. Hanani. 1984. Physiological and pharmacological studies of internal anal sphincter in the rat. J. Pediatr. Surg. 19:12-14.

5. Nurko, S., and S. Rattan. 1988. Role of vasoactive intestinal polypeptide in the internal anal sphincter relaxation of the opossum. $J$. Clin. Invest. 81:1146-1153.

6. Furness, J. B., and M. Costa. 1973. The ramifications of adrenergic nerve terminals in the rectum, anal sphincter, and anal accessory muscles of the guinea pig. Z. Anat. Entwicklungsgesch. 140:109-128.

7. Burleigh, D. E., and A. D'Mello. 1983. Neural and pharmacologic factors affecting motility of the internal anal sphincter. Gastroenterology. 84:409-417.

8. Bouvier, M., and J. Gonella. 1981. Nervous control of the internal anal sphincter of the cat. J. Physiol. (Lond.) 310:457-469.

9. Drew, G. M. 1976. Effects of alpha-adrenoceptor agonists and antagonist on pre- and postsynaptically located alpha-adrenoceptors. Eur. J. Pharmacol. 36:313-320.

10. Bulbring, E., and T. Tomita. 1987. Catecholamine action on smooth muscle. Pharmacol. Rev. 39:49-96.

11. Minneman, K. P. 1988. Alpha-1 adrenergic receptor subtypes, inositol phosphates and sources of cell $\mathrm{Ca}^{2+}$ Pharmacol. Rev. 40:87119.

12. Culver, P. J., and S. Rattan. 1986. Genesis of anal canal pressures in the opossum. Am. J. Physiol. 251:G765-G771.

13. Cambridge, D., M. J. Davey, and R. Massingham. 1977. Prazosin, a selective antagonist of post-synaptic alpha-adrenoceptors. $\mathrm{Br}$. J. Pharmacol. 59:524-515.

14. Goldberg, M. R., and D. Robertson. 1983. Yohimbine: a pharmacological probe for study of the alpha $a_{2}$-adrenoceptor. Pharmacol. Rev. 35:143-180. 
15. Rattan, S., and R. Shah. 1987. Influence of sacral nerves on the internal anal sphincter of the opossum. Am. J. Physiol. 253:G345G350.

16. Snedecor, G. W., and W. G. Cochran. 1967. Statistical Methods. 6th ed. Iowa State University Press, Ames, IA.

17. Nurko, S., and S. Rattan. 1990. Role of neuropeptide $Y$ in opossum internal anal sphincter. Am. J. Physiol. 258:G59-G64.

18. Rudd, P., and T. F. Blasschke. 1985. Antihypertensive agents and the drug therapy of hypertension. In The Pharmacological Basis of Therapeutics. A. G. Goodman, L. S. Gilman, T. W. Rall, and F. Murad, editors. 7th ed. Macmillan Publishing Co., New York. 784-805.

19. Wikberg, J. E. S., and R. J. Lefkowitz. 1982. Alpha ${ }_{2}$ adrenergic receptors are located prejunctionally in the Auerbach's plexus of the guinea pig small intestine: direct demonstration by radioligand binding. Life Sci. 31:2899-2905.

20. Denny-Brown, D., and G. Robertson. 1935. An investigation of the nervous system of defecation. Brain. 58:256-306.

21. Schuster, M., T. R. Hendrix, and A. I. Mendeloff. 1963. The internal anal sphincter response. Manometric studies on its normal physiology, neural pathways, and alteration in bowel disorders. J. Clin. Invest. 42:196-207.

22. Lubowski, D. Z., R. J. Nicholls, M. Swash, and M. J. Jordan.
1987. Neural control of internal anal sphincter function. Br. J. Surg. 74:668-670.

23. Christensen, J. 1989. Colonic motility. Handb. of Physiol. 1:939-974.

24. Fargeas, M. J., J. Fioramonti, and L. Bueno. 1986. Central alpha2-adrenergic control of the pattern of small intestinal motility in rats. Gastroenterology. 91:1417-1475.

25. Galligan, J. J. 1983. Clonidine inhibits intestinal motility in the rat: central and peripheral sites of action. Gastroenterology. 84:1404a. (Abstr.)

26. Issac, L. 1980. Clonidine in the central nervous system: site of mechanism of hypotensive action. J. Cardiovasc. Pharmacol. 2:S5S19.

27. Jiang, Q., R. J. Sheldon, and F. Porreca. 1988. Sites of conidine action to inhibit gut propulsion in mice: demonstration of a central component. Gastroenterology. 95:1265-1271.

28. Merlo, A., and S. Cohen. 1988. Neuropeptide responses and mechanisms of the proximal and distal feline colon in vitro. Am. J. Physiol. 255:G787-G793.

29. Guiterrez, J. G., and A. N. Shah. 1975. Autonomic control of the internal anal sphincter in man. In Fifth International Symposium of Gastrointestinal Motility. G. Van Trappen, editor. Typoff-Press, Leuven, Belgium. 363-373. 